When you're smiling: exploring how teachers motivate and engage learners in the further education sector.

Susan Wallace,

School of Education, Nottingham Trent University, Nottingham, UK

sue.wallace@ntu.ac.uk

Sue Wallace is Professor of Continuing Education at Nottingham Trent University where she is involved with the initial teacher training and continuing professional development of teachers in the further education sector. 


\title{
When you're smiling: exploring how teachers motivate and engage learners in the further education sector.
}

\begin{abstract}
This paper is based on a one year research project in the UK designed to investigate teachers' strategies for motivating learners and managing non-compliant behaviour in the Further Education sector. Carried out in collaboration with 203 teachers in three colleges of further education, the inquiry set out to identify, through the use of observations and focus groups, the learner behaviours most commonly identified by teachers as 'challenging', and the methods teachers employ to successfully address these. It also sought to capture teachers' theories about the possible causes of non-engagement, with a view to incorporating findings about both theorising and practice into sessions for initial teacher training and continuing professional development. Drawing on these data, this paper suggests that lack of motivation in the 14-19 age group is a common phenomenon across this range of colleges, manifesting in behaviours such as lack of punctuality, failure to submit coursework and refusal to remain on task; and that experienced teachers are no more effective in managing such behaviours than teachers new to the profession. The implications in terms of teacher education and development are discussed in the final section which points to the evidence that, although positive teacherlearner interaction is found to be productive in addressing the immediate symptoms of disengagement, participants in the study consider the root causes to lie beyond their control.
\end{abstract}

Keywords: professional development; motivation; behaviour; further education.

\section{A. Introduction}

The further and vocational education sector in the UK is currently in the strange position of being unsure what to call itself. The term 'Lifelong Learning' has become associated with a set of policy initiatives instigated by the Labour governments of 19972010 which have subsequently been overturned, beginning with the dissolution of Lifelong Learning UK (LLUK), the sector skills council set up in 2005 to regulate the 
professional development of teachers and trainers in the post-compulsory sector and to manage what had become known as the 'LLUK standards' for teacher training. Following a period of uncertainty between this dissolution and the publication of the findings of the Lingfield Review (2012), it is now apparent that teachers for the sector will still be expected to gain a sector-specific teaching qualification. Meanwhile, the terminology employed by the sector to describe itself is reverting to some of its previous, non-politicised aliases: Further Education (FE); Further Education and Training (FET); Vocational Education and Training (VET); or Post-compulsory Education and Training (PCET). Colleges of Further Education play a key role in this sector, and it is the teaching and learning in such colleges which provides the context for this research. Therefore ' $\mathrm{FE}$ ' will be the term used in this paper to indicate the sector as a whole.

When embarking on their training, applicants to the profession are often asked why they have chosen to teach in further education rather than in schools; and their answer often makes reference to their belief that learners in this sector are there because they want to be, and are therefore likely to be more highly motivated and better behaved than those who are still in school and subject to compulsory attendance (Wallace, 2007). Their first days of observing experienced teachers at work in the sector are often experienced as a sharp contrast to these preconceptions (Wallace, 2002; Spenceley, 2007) as the extent of de-motivation and non-compliance among some groups of learners becomes apparent. The purpose of the research described in this paper, therefore, was three-fold: it was designed to discover the most frequently encountered examples of disengaged or non-compliant student behaviour observed in a sample of three colleges of further education; to explore the strategies which teachers and trainers employed to successfully address these; and to extrapolate, where possible, the 
theorizing that underpinned teachers' strategies. The ultimate purpose of this categorization and exploration was to inform the content of university-based teacher training sessions and programmes of continuing professional development (CPD) for the sector, so as to encourage teachers and trainee teachers in a critical and analytical approach towards student motivation and behaviour, as well as offering them a repertoire of relevant skills. The research was carried out as a collaborative project between a UK University and three centres of FE: one serving a wide area combining both rural and urban populations; one serving a disadvantaged urban population; and the third drawing its students from a small town with a fluctuating Traveller population.

Low levels of motivation and high levels of disengagement among some groups of 14-19 year olds on vocational courses in colleges of FE have become increasingly apparent over the past two decades (for example: Reeves, 1995; Ainley and Bailey, 1997; Wallace, 2002; Fuller and Macfayden, 2012). A number of explanations have been offered for this, as we shall see in the following section, ranging from the nature of the vocational curriculum itself to the argument that learners find themselves on such courses by default rather than through choice. It is also relevant to this inquiry that, from 1999 to 2010, there was a clear policy discourse asserting the need for a qualification linked to professional standards for teachers in this sector of education and training; a discourse whose subtext could be taken to suggest that learners' poor behaviour and lack of motivation may be due to some deficiency in the standard of teaching they receive (Wallace, 2007). The current indications that this policy may change (Lingfield, 2012) do not necessarily signal an end to what Ball (1990:18) terms a 'discourse of derision'. It is important, therefore, to stress that the research described in this paper sought to identify good practice not as a means to 'correct' teachers whose styles or strategies are unsuccessful in encouraging students to engage with their 
learning, but rather as a pragmatic approach to discovering and sharing what works most successfully (Moore, 2004). Its aim was not uniformity of teaching approach, but to equip teachers with a repertoire of possible strategies and theories which they could employ in the best interests of the learners.

\section{B. Themes in the literature}

While there is no shortage of literature relating specifically to the behaviour management and motivation of learners in the context of compulsory education, there is much less relating to the further education sector. However, although, as we have seen, there is a commonsense assumption that 'post-compulsory' equates with 'voluntary', there is nevertheless a section of literature aimed at FE practitioners which falls into the instrumental 'how to' category (for example, Vizard, 2012; Wallace, 2007a; Wallace, 2007b). This literature offers strategies and advice for teachers and is relevant to this research in two ways. Firstly, such strategies and their degree of success might be expected to be observed during the gathering of data. Secondly, such literature is inevitably predicated on a simplified causal model in that it appears to saying to the teacher, 'If you adopt this strategy the learners will be more likely to behave themselves'; an instrumental approach to some extent shared by this research in as far as one aim is to give practical support for professional development. More problematic, however, is the notion of a deficit model of teachers or learners, or indeed both, which this inquiry - like the range of 'how to' books - might be seen to imply. It is important to take into account, therefore, the significant thread of literature which argues that the origins of learner disaffection in FE lie outside the individual teacher's power to remedy or control. In this context, teachers' behaviour management and motivational strategies are understood as ways of dealing with symptoms whose underlying causes are 
systemic and endemic. This literature can be categorized into four broad arguments relating to the causes of learners' disengagement. These may be summarized as:

- socio-economic issues and the design of the vocational curriculum;

- perceptions of the sector, its status and purpose;

- the instrumentalism of FE teachers' occupational standards;

- the question of student choice in a competitive market.

Each of these will be explored briefly here under its own heading before the common themes are summarized in the context of this inquiry.

\section{B1. Socio-economic issues and the design of the vocational curriculum}

The competence-based, instrumental nature of the vocational curriculum in the UK following the introduction of National Vocational Qualifications in 1986 has meant that, for example, the provision of a wider curriculum based on a liberal education model and incorporating 'liberal' or 'general' studies such as the discussion of literature, politics or social issues was discontinued for vocational students. Instead their learning is tightly focused on preparing them to demonstrate their competence against a set of occupational standards at a level considered appropriate to them. It has for some time been argued (for example: Reeves, 1995; Wolf, 2011) that the repetitious, instrumental nature of the competence-based curriculum encourages young learners to see the process of learning as a 'can do' tick list, and thereby fails to engage their enthusiasm for deeper levels of understanding or for learning per se. When Reeves argues that this instrumental curriculum encourages a 'tacit acceptance that proper education is rewarded with accreditation not by gratification' (1995: 105), we hear an echo of William Morris (1834-1896) and his famous condemnation of 'useless toil', which he defined as effort which carries no 'hope of pleasure in our 
daily creative skill’ (Morris, 1888: 4). Alternatives to the instrumentalist curriculum have been posited by, for example, Pring (2002) who argues for a form of 'liberal vocationalism' which strenuously rejects the concept of learning as a set of competencies; and by Clarke and Winch (2007) who argue, amongst other things, for a model more closely aligned with the German dual system.

In a socio-economic climate where competence-based accreditation cannot guarantee success in the job market, the learners are well aware of the low value frequently placed upon the qualifications for which they are being urged to work (Wolf, 2011). These elements are further compounded by issues of status and class, with colleges of further education recruiting a much higher percentage of students from lower socio-economic backgrounds than sixth forms and sixth form colleges (Foster, 2005) and generally students from a middle class background with relatively low academic achievement (Thompson, 2009); demographic factors which may serve to perpetuate negative notions about the value and desirability of the FE curriculum.

\section{B.2 Perceptions of the sector, its status and purpose}

Wolf's description of the FE sector as a provision 'for other people's children' (2002:56) acknowledges with irony the commonsense perception of FE as still predicated on nineteenth century notions of class and status, where 'useful knowledge' was what constituted the curriculum for the labouring and artisan classes, and where education gained in status the further removed it was from serving the world of work (Wallace, 2013). What Swift and Fisher (2012) refer to as 'the ambivalent status surrounding vocational education' (207) may not only, as they argue, deter ambitious students from entering the sector at 16 , but may also depress levels of motivation and engagement in some of those for whom it is the only option. Certainly, research suggests that the aspirations of learners in FE tend to be lower than those of learners 
who continue their post-16 education in schools (Baird et al, 2012). Moreover, since the purpose of the sector has been confirmed as one of skills training (Foster, 2005), its position and status in our current 'knowledge society' is open to question (Bathmaker, 2005); and this may go some way to explain why the sector has come to be seen as a progression route for those who have failed at school (Thompson, 2009). The devaluing of skills training in a knowledge economy is not in itself peculiar to the UK. Crawford (2011) for example, points out that in American schools, too, 'the manual trades are given little honor' (19); and suggests that this is because 'craftsmanship entails learning to do one thing really well, while the idea of the new economy is to be able to learn new things' (ibid). From the learner's point of view, these prevailing notions about the sector and its status may undermine self-esteem and throw doubt on the value and purpose of engaging with the FE curriculum.

\section{B.3 The instrumentalism of FE teachers' occupational standards}

Lucas (2007) argues that basing teacher training for the sector on 'standards' rather than on 'knowledge' leads to a failure to acknowlege the complex processes and motivations involved in the learning process, giving undue emphasis instead to the idea of vocational education and work-based learning as little more than learning by doing. This is not an issue restricted to the UK. Woodcock and Vialle (2010), for example, draw attention to the deficit model which they argue is apparent in teacher training frameworks for the Technical and Further Education (TAFE) sector in Australia. The introduction of such frameworks as a measure to improve student engagement is open to the criticism that learner behaviour and motivation are unlikely to be improved without first addressing political and socio-economic questions, such as the lack of employment for college leavers (Wallace, 2002). The instrumental nature of the current 
framework could be viewed as detrimental to FE teachers' sense of self-efficacy and professionalism, since the very debate about what constitutes 'professionalism' includes the suggestion that teachers see it as lying in the willingness and ability to perform beyond the curriculum requirements (Robson et al, 2004) which might include ways of relating to learners or enhancing the teacher's theoretical understanding of what factors will best motivate and engage them. The principles of andragogy (Knowles, 1984) where the instrumental concept of 'educating people' is transformed into the supportive, democratic, less hierarchical idea of 'helping them to learn' are discounted or marginalised by a competence-based curriculum which, in Freire's terms, could be described as a ‘banking’ (1996) approach to learning. Freire’s ideal of education as transformation, based on an approach where the relationship between educator and educatee is construed as an interaction of equals, not of instructor and instructed, is similarly sidelined by current requirements and practices. However, as Moore (2004) points out, the priority for most teachers is effectiveness, and this predisposes them to prioritise strategies that work, over standardised 'competences'.

\section{B.4. The question of student choice in a competitive market}

Since the 1988 Education Reform Act introduced Local Management of Schools (LMS), a quasi-market has operated in UK post-16 education and training, further strengthened subsequently by The Further and Higher Education Act of 1992. It is perhaps unsurprising, therefore, that the impartiality of progression advice provided by schools, in the form of information, advice and guidance may be compromised by the imperative to compete for the most able learners (Fuller and Macfadyen, 2012). Perhaps inevitably in a culture of competition, it is the schools, not the students, who have the 
final choice over who will stay on after the age of 16; and, driven by performance targets, schools and sixth form colleges will tend to recruit or retain pupils at 16 on the basis of academic achievement (Swift and Fisher, 2012). Moreover, research suggests that the information and guidance schools provide about vocational qualifications may be inadequate (ibid). The extent to which students themselves are able to make a free and informed choice about whether or not to enter the further education sector may, therefore, be seen as questionable (Wallace, 2007). These factors - lack of adequate guidance or a failure to be chosen to stay on at school - may result in learners finding themselves, by default, in FE colleges on vocational programmes that they have not in any real sense ‘chosen’ (Fuller and Macfadyen, 2012) and which may not coincide with what they consider to be their needs or aspirations (Ball, Maguire and Macrae, 2000; Wallace, 2007).

\section{B. 5. A summary of the literature}

As we have seen, previous research offers us a number of explanations for the low level of motivation and the negative behaviour which FE teachers may encounter amongst their students. All of these explanations have factors in common. They suggest that the origins of the problem can be found at a policy level, whether it is the application of market ideology to educational institutions and processes, or the categorising of teaching skills as a set of competences. They argue that these policies, serve to some extent to disempower the teacher and destabilise the profession. And, perhaps most important of all in the context of this research, they offer an alternative discourse to that which presents learner disengagement as being an indicator of deficient teaching.

\section{Method and methodology}


It is important to reiterate here that the research set out to discover not what teachers might be doing 'wrong', but rather what worked (Moore, 2004) in terms of facilitating students' engagement with their learning. To this end, it was necessary to observe teachers across as wide a possible range of subjects and at all levels of the 16-19 vocational curriculum. A total of 183 classes were observed across three FE colleges. This constituted an opportunity sample, and included teachers in their first year of teaching as well as experienced practitioners. Observation in itself presents the researcher with obvious difficulties in terms of reliability (Wragg, 1999), not least because of the subjective and interpretative nature of observation findings. Lesson observations, in FE specifically, are associated in teachers' minds with inspections and performance management (O’Leary, 2012), a factor which could make them reluctant to participate. The presence of an observer would inevitably impact upon the dynamics of teacher-student and student-student interactions for the duration of the observation (Wragg, 1999), and perhaps particularly so if the observer was an unfamiliar 'outsider'. The pressure to 'perform' may lead the teacher to implement strategies they might not otherwise use, thus affecting the validity of the data; and, even where reassurances are given that the observation is will be judgement-free, the question of the implicit power relationship between observer and observed cannot be ignored (ibid). Therefore, drawing on evidence that teachers in the sector acknowledge the usefulness and value of peer observation (Peake, 2006; Burrows, 2008) it was decided to embed the observations in the peer observation arrangement which each of the colleges implemented regularly as part of its self assessment framework. This meant that the observations would be carried out during the course of a familiar procedure and by familiar staff, thus minimizing their impact on normal interactions. 
The use of observers other than the researchers themselves, however, created a different set of potential difficulties, as different observers might each have their own interpretation of what constituted key terms such as 'compliant behaviour' and might hold differing views on what constituted 'effectiveness' in terms of teachers' motivational or behaviour management strategies. In order to address this, all 20 peer observers were fully briefed about the purpose of the research and its terms of reference, and were provided with written definitions and examples of the behaviours and strategies they were asked to note, as well as a standardized pro-forma on which to record their observations. Their brief was to:

- 'Note all examples of learner behaviour or interaction which falls into the category of "lack of motivation” or the category of “non-compliant behaviour”, as defined on your briefing sheet.

- Note all strategies used by the teacher which successfully addressed these.'

A 'successful' strategy was defined as one which brought about an improvement in engagement or behaviour which lasted until the end of the lesson being observed.

These measures were designed to raise levels of reliability and validity as far as was possible. As with all qualitative research which relies for its data on the observation of, and response to, complex human interactions, this methodological approach raises a number of epistemological issues, including the questions about the extent to which we can take the resulting observations as a basis for claims to knowledge about what 'works' in the classroom and what does not. Hammersley (2008) points out the potential pitfall for qualitative researchers of making claims about cause and effect which cannot be substantiated by the evidence. How reliable would be the notion, for example, that an improvement in learner behaviour was as a direct result of a specific teacher intervention? It was considered that one indicator would be the degree 
of consistency in the resulting data from 183 observations by 20 observers across three colleges, and this will be explored further in the next section.

The observations were followed by a focus group meeting of the observers during which the group discussed with the researchers the process (that is, their experience) of the observations; the resulting data; and their own accounts or theoretical understandings of learner disengagement and the teacher's role. The focus group was conducted on an informant rather than a respondent model (Powney and Watts, 1987), where the participants were invited to address very open questions with prompts such as, 'Tell us something about your findings.' The purpose of the informant approach is to allow the participants to open up ideas or areas of discussion which the researchers may not have thought of. It does not, like the respondent approach, restrict participant input to within the parameters delineated by researchers' questions (Atkins and Wallace, 2012). In other words, it allows for the exploration of the unforeseen. In this way the observers, as participants, were encouraged to theorize from the data collected and to share their understanding of its meaning and significance. The research was conducted in conformity with the British Educational Research Association (BERA) ethical guidelines (2011). All participants, whether observers or observed, provided their informed consent and were told of their right to withdraw at any stage of the inquiry.

\section{Discussion of Findings}

The results of the observations and the outcomes of the focus group discussion can be categorized as follows: 
- Most frequently observed examples of unmotivated or non-compliant behaviour.

- Strategies seen to be most effective in addressing these.

- Focus group's reflection on the findings and their theorizing about the causes of low motivation and non-compliance in 14-19 year old learners.

Each of these will be discussed under its own heading before the findings as a whole are summarized at the end of this section.

\section{1. Most frequently observed examples of unmotivated or non-compliant}

\section{behaviour}

According to the observers' notes, the most frequently occurring indicators of noncompliance or disengagement in the 183 classes observed were:

- lack of punctuality (171 instances recorded);

- talking while the teacher is speaking or instead of concentrating on a task, so that noise levels constitute a potential barrier to other students' learning (168 instances recorded);

- the use of phones during class time, for calls and messaging or accessing the internet or playing games (132 instances recorded);

- rude or confrontational behaviour which demonstrated a lack of respect for the teacher and/or fellow students (103 instances recorded);

- not handing work in at the required time (62 instances recorded).

There are several things to note about this list. The first is that most of these behaviours demonstrate what we might call 'low level' non-compliance, and do not, on the whole, include violent, aggressive or criminal activity. The second is that, despite being nonserious in that sense, all of these have the potential to disrupt the learning of other 
students who might be better motivated or would choose to be more compliant. Thirdly, it emerged that this range of behaviour in 16-19 year old learners was found across all vocational areas, at all levels of qualification, and among all groups. There was found to be no correlation between the age or gender or length of professional experience of the teacher and the frequency of these behaviours, nor between vocational area or subject and such behaviours. Moreover, this data presented as consistent across all three colleges.

\section{D.2. Strategies seen to be most effective in addressing these}

In contrast to the consistent data which emerged on behaviours, the observations produced no such clear-cut evidence about the efficacy of teachers' strategies for dealing with them. In this sense the findings were disappointing. However, and perhaps more significantly, there were indications that teachers had most success in building student motivation and encouraging positive behaviour in cases where the relationship between teachers and learners appeared positive, cheerful and mutually respectful. Representative and illustrative of observations recorded under the heading of 'Strategies used by the teacher which successfully addressed these', are descriptions such as: 'joked her out of it'; 'kept it light and kept smiling'; 'chatted with him in a freindly [sic] way'; 'had a laugh with them about it'; 'jollied him up'; 'didn't get mad but showed he was concerned in a nice way'; 'got her mind off it by making her laugh'; 'firm but made it obvious she was being kind and caring'. To categorize the interactions described in this way as strategies seems to miss something of their affective or interpersonal quality.

This aspect of the findings was discussed in the focus group. Initially the group sought to explore the causal relationship between positive, cheerful teaching and well- 
motivated learners, since it could be justifiably and as easily claimed in theory that motivated learners produce cheerful teachers. The majority view, however, was that a crucial factor in motivating students seemed to be the attitude and demeanor of the teacher; and that they were unsurprised that the observations had demonstrated this repeatedly. Instead of strategies, then, what emerged from the focus group's discussion of their observations was rather a set of conditions under which vocational students are most likely to exhibit motivation and positive, appropriate behaviour; and that these conditions are recognized as necessary by the 'cheerful' teachers, who adjust their planning and teaching to create or accommodate them. These conditions can be articulated in the following way: That students engage with learning

- when they have the ability to do the task;

- $\quad$ when they can see some point in doing it;

- when they can take some pride in doing it;

- when doing it fits their image of who they are.

The evidence further suggests that teachers' experience or length of service is not a correlating factor in relation to recognising the importance of these conditions or of adopting a positive and 'cheerful' demeanour. It was unclear, however, whether those teachers whose observed practice reflected this list and/or the 'cheerful' approach could or would articulate these as factors which played a role in their successful motivation of students. In other words, there remains a question about the extent to which they owed their success to reflection or conscious theorising on their own practice rather than to a natural disposition, a high level of emotional intelligence or instinctive pragmatism. 


\section{D.3. Focus group's theorizing about the causes of low motivation and non- compliance in 14-19 year old learners}

Perhaps some of the most interesting, if least anticipated findings to come out of the focus group discussion were the theories that teachers/observers put forward to explain the low levels of motivation and the disruptive behaviour of some sections of the FE student population. One theory popular in the focus group was that some learners' lack of concentration did not arise from inability or unwillingness but from the fact that they arrived at college without having eaten breakfast or, in some cases, with inadequate clothing in cold weather. There was a general consensus that standards of behaviour at college were primarily influenced by the learners' home environment and by whether parents or carers were generally supportive of college rules or of teachers' attempts to inculcate good manners and safe practices. There was also agreement that learners could be encouraged towards appropriate behaviour by demonstrations or explanations of what was required in the workplace, so that, for example, hairdressing students understood and responded to the need for politeness and helpfulness in a salon environment, and trainee electricians would abide by work-related safety protocols. This correlation between appropriate behaviour and vocational area did not, however, emerge as a significant factor in the observation reports.

It is interesting to note that, although the focus group suggested that causes of student disengagement lay outside the control of the individual teacher, none of these were factors identified in the literature reviewed above - including the instrumental nature of the vocational curriculum (Bathmaker, 2005; Wolf, 2011); weaknesses in the professional qualification for vocational teachers (Lucas, 2007; Woodcock and Vialle, 2010); lack of learner choice and the pressures of market ideology (Fuller and Macfadyen, 2012; Swift and Fisher, 2012). Neither did the group identify a lack of 
specific pedagogic skills on the part of teachers as contributing to learners' disengagement.

\section{Summary of findings}

Taken together, the data from the observations and the focus group discussion suggest that learner disengagement in the 14-19 age group is observable across all vocational areas in the FE provision explored in this inquiry. Links were suggested between disengagement and learner deprivation; and between learner disengagement and attitudes learned in the home environment. No specific teaching strategies for motivation or control were identified as being consistently successful. However, there appeared to be a correlation between teachers' apparent 'cheerfulness' and positive levels of learner motivation and behaviour. This was also described in terms of teachers demonstrating a sense of humour and an ability to interact with groups of learners in ways that implied positive regard. This is consistent with research which suggests that some learners in FE report finding a more relaxed and mutually respectful teacherlearner relationship than they experienced at school, and feeling, as a consequence, more confident about engaging with their learning (for example, Fuller and Macfayden, 2012; Peart, 2012). Similar findings have also emerged from recent research into learner engagement higher education (HE) (for example, Hunt, 2012) which suggests that the relationship between learner and teacher is a factor in encouraging deeper learning. However, it should be noted that the HE focus here is on class size and its impact on opportunities for one-to-one interaction with the teacher, rather than specifically on the teacher's attitude or approachability. 


\section{Conclusion}

Part of the purpose of this research project, as set out in the introduction, was to identify strategies used successfully by teachers in FE to improve learner motivation and behaviour. However, although the evidence gathered suggests that some degree of disengagement of young learners in the UK's FE colleges may be endemic, it also raises important questions about the logic and efficacy of addressing such disengagement simply by revisions to teacher training and continuous professional development programmes. While pointing to a link between disengagement and learned attitudes towards education and training, it nevertheless suggests that the key to motivating the learners in question - inasmuch as it lies with their teachers at all - consists in certain teacher attitudes and attributes rather than skills or strategies. Indeed, in suggesting that a positive teacher-learner relationship is a major factor in the motivation to learn, these findings appear to be consistent with the arguments of Knowles (1984) and Freire (1996) in their emphasis on a supportive rather than hierarchical teacher-learner relationship. They can also be seen as reflecting humanist theories of learning associated with Maslow (1987) and Rogers (1983), which argue that students' more basic needs - for acceptance and a sense of belonging, for example - must be met before they can engage with the business of learning. Teachers' own sense of well-being and empowerment may also be a factor here, as suggested by Woodcock (2011) in his Australian study into the link between teachers' sense of self-advocacy and learners’ levels of motivation.

However, it is not easy to see how teachers' development of such attributes, values and beliefs can be addressed by the existing instrumental and competence-based set of teaching standards. Indeed, it opens up questions about what we mean by a 'good' FE teacher and about the criteria by which policy makers may require their competence 
to be measured and found wanting. Meanwhile, it remains to be seen whether current policy discourses around revision or replacement of the standards and the status and nature of qualifications for teaching in the sector will encourage teachers towards a more relationship-based and pragmatic 'pick and mix approach’ (Braun, 2012: 237) to engaging the de-motivated and underachieving section of the FE student population.

\section{References}

Ainley, P. and Bailey, B., 1997. The business of learning: staff and student experiences of Further Education. London: Cassell.

Atkins, L. and Wallace, S., 2012. Qualitative research in education. London: Sage.

Ball, S., 1990. Politics and policy making in education: explorations in policy sociology. London: Routledge.

Ball, S., Macrae, S., and Maguire, M., 2000. Choice, pathways and transitions post-16: new youth, new economies in the global city. London: Routledge.

Braun, A., 2012. Trainee teachers, gender and becoming the 'right' person for the job: care and authority in the vocational habitus of teaching. Oxford Review of Education, 38 (2), 231-246.

Burrows, J., 2008. Trainee perceptions of observation. Huddersfield: Huddersfield Consortium.

Clarke, L., and Winch, C., eds., 2007. Vocational Education: International approaches,developments and systems. London: Routledge.

Crawford, M., 2011. The case for working with your hands. London: Penguin.

Foster, A., 2005. Realising the potential: a review of the future role of further education colleges. Annesley, UK: DfES.

Freire, P., 1996. The pedagogy of the oppressed. London: Penguin Education

Fuller, C. and Macfadyen, T., 2012. 'What with your grades?' Students' motivation for and experiences of vocational courses in further education. Journal of Vocational Education and Training, 64 (1), 87-101.

Hammersley, M., 2008. Questioning qualitative inquiry. London: Sage

Hunt, C., 2012. Learning in large spaces: the academic engagement of a diverse group of students. Research in Post-Compulsory Education, 17:12, 195-205.

Knowles, M., 1984. Androgogy in action: applying modern principles of adult learning. US: JosseyBass.

Lingfield et al., 2012. Interim review of professionalism in further education. Available from: http://www.bis.gov.uk/assets/biscore/further-education-skills/docs/p/12-670-professionalism-infurther-education-interim.pdf [Accessed $12^{\text {th }}$ January, 2013]

Lucas, N., 2007. Rethinking initial teacher education for further education teachers: from a standardsled to a knowledge-based approach. Teacher Education, 18(2), 93-106.

Maslow, A.,1987. Motivation and personality. New York: Harper and Row.

Moore, A., 2004. The good teacher: dominant discourses in teaching and teacher education. London: Routledge.

Morris, W., 1888/2008. Useful work versus useless toil. London: Penguin.

O’Leary, M., 2012. Exploring the role of lesson observation in the English education system: a review of methods, models and meanings. Professional Development in Education, 38(5), 791-810.

Peake, G., 2006. Observation of the practice of teaching. Huddersfield: Huddersfield Consortium.

Peart, S., 2012. The impact of culture on participation: Black men and boys' experience of further education. Race Equality Teaching, 3, 7-9. 
Powney, J; and Watts, M., 1987. Interviewing in educational research. London: Routledge and Kegan Paul.

Pring, R., 2002. Liberal Education and Vocational Preparation. In R. Barrow and P. White, eds. Beyond Liberal Education: Essays in Honour of Paul H. Hirst. London: Publisher, 49-79

Reeves, F., 1995. The modernity of further education. Bilston and Ticknall: Bilston College Publications.

Robson, J; Bailey, B. and Larkin, S., 2004. Adding value: investigating the discourse of professionalism adopted by vocational teachers in further education colleges. Journal of Education and Work, 17(2), 183195.

Rogers, C., 1983. Freedom to learn for the 80s. London: Merrill.

Spenceley, L., 2007. 'Walking into a dark room': the initial impressions of learner-educators in further education and training. Journal of Further and Higher Education, 31 (2), 87-96.

Swift, J. and Fisher, R., 2012. Choosing vocational education: some views from young people in West Yorkshire. Research in Post-Compulsory Education, 17:2, 207-221.

Thompson, R., 2009. Social class and participation in the further education: evidence from the Youth Cohort Study of England and Wales. British Journal of Sociology of Education, 30 (1), 29-42.

Vizard, D., 2012. How to manage behaviour in further education. London: Sage.

Wallace, S., 2002. No good surprises: intending lecturers' preconceptions and initial experiences of further education . British Educational Research Journal, 28 (1), 79-93.

Wallace, S., 2007a. Managing behaviour and motivating learners in the lifelong learning sector. 2nd ed. Exeter: Learning Matters.

Wallace, S., 2007b. Getting the buggers motivated in FE. London: Continuum.

Wallace, S., 2013. Choosers or losers? Progression from school to lifelong learning in the UK. Annali della Didattica e della Formazione docente, Special Issue: School and lifelong learning. 5/2013 (in press)

Wolf, A., 2002. Does education matter? Myths about education and economic growth. London: Penguin.

Wolf, A., 2011. Review of Vocational Education (The Wolf Report). London: Department for Education

Woodcock, S., 2011. A cross-sectional study of pre-service teacher efficacy throughout the training years. Australian Journal of Teacher Education, 36 (10), 22-34.

Woodcock, S. and Vialle, W, S., 2010. Attributional beliefs of students with learning disabilities. International Journal of Learning, 17 (7), 177-191.

Wragg, E.C., 1999. An introduction to classroom observation. $2^{\text {nd }}$ ed. London: Routledge. 